\title{
Cutaneous manifestations of COVID-19: experience from a tertiary care center for COVID-19 management in South India
}

\author{
Olasseri K. R. Mariyath ${ }^{1 *}$, Sreekanth Sukumarakurup ${ }^{1}$, Koyakutty A. Samad ${ }^{1}$, \\ Keerankulangara Devi ${ }^{1}$, George Nikhil ${ }^{1}$, Ulpurath Minu ${ }^{1}$, \\ Premachandran Mekha ${ }^{1}$, Mohamed Shaan ${ }^{2}$
}

\begin{abstract}
${ }^{1}$ Department of Dermatology and Venereology, ${ }^{2}$ Department of General Medicine, Govt. Medical College, Kozhikode,
\end{abstract} Kerala, India

Received: 04 November 2020

Accepted: 08 December 2020

*Correspondence:

Dr. Olasseri K. R. Mariyath,

E-mail: mariyath71@gmail.com

Copyright: (C) the author(s), publisher and licensee Medip Academy. This is an open-access article distributed under the terms of the Creative Commons Attribution Non-Commercial License, which permits unrestricted non-commercial use, distribution, and reproduction in any medium, provided the original work is properly cited.

\begin{abstract}
Cutaneous manifestations observed in COVID-19 include maculopapular rash, urticaria, pseudo chilblain, vesicles, livedo reticularis, petechiae, erythema multiforme-like, symmetric drug related intertriginous and flexural exanthem (SDRIFE)-like and pityriasis rosea-like lesions. Maculopapular rash involving the trunk and sparing palms and soles is the most common cutaneous manifestation reported in COVID-19 patients. We report cutaneous manifestations in six COVID-19 patients from the corona isolation ward and intensive care unit of a tertiary care center for COVID-19 management in Kerala, South India. The skin lesions observed were urticaria (two patients), atypical maculopapular rash with urticarial and erythema multiforme-like lesions, eruptive pseudoangiomatosis, exaggerated insect bite reaction and acute localized exanthematous pustulosis (ALEP)-like lesions. To the best of our knowledge atypical maculopapular rash with urticarial and erythema multiforme-like lesions, eruptive pseudoangiomatosis and acute localized exanthematous pustulosis-like lesions are not reported in COVID-19.
\end{abstract}

Keywords: COVID-19, Cutaneous manifestations, Experience, South India

\section{INTRODUCTION}

Coronavirus disease 2019 (COVID-19) is caused by severe acute respiratory syndrome coronavirus-2 (SARS$\mathrm{CoV}-2)$ which is an enveloped ribonucleic acid (RNA) beta corona virus. SARS-CoV-2 was first isolated from the city of Wuhan in China. ${ }^{1}$ Many cutaneous manifestations of COVID-19 have been reported. Maculopapular rash, urticaria, pseudo chilblain, vesicles, livedo reticularis, petechiae, erythema multiforme-like lesions, symmetric drug related intertriginous and flexural exanthem (SDRIFE)-like and pityriasis rosea-like lesions are reported in COVID-19 patients. $^{2-5}$ We report cutaneous manifestations in six COVID-19 patients from Government Medical College, Kozhikode, Kerala, which is a tertiary care center for COVID-19 management in
South India. Urticaria (two patients), atypical maculopapular rash, eruptive pseudoangiomatosis, exaggerated insect bite reaction and acute localized exanthematous pustulosis (ALEP)-like lesions were observed in COVID-19 patients.

\section{CASE SERIES}

\section{Case 1}

A 24-year-old male presented with itchy red raised lesions of the face, trunk and limbs followed by high grade fever, redness and watery discharge from eyes. He consulted a dermatologist and was treated with parenteral ceftriaxone, pheniramine maleate and oral doxycycline with differential diagnosis of maculopapular rash and erythema 
multiforme due to rickettsial infection. The patient was referred to our center for further work up and management.

On examination the patient was afebrile and vitals were stable. He had multiple discrete and confluent erythematous papules and plaques of size ranging from $0.5 \times 0.5 \mathrm{~cm}$ to $5 \times 4 \mathrm{~cm}$ involving face, trunk, limbs, palms and soles (Figure 1). A few targetoid lesions were present on the forearms and soles. There was mild congestion of conjunctivae. Rapid antigen test for COVID-19 was done as per standard protocol which was positive.

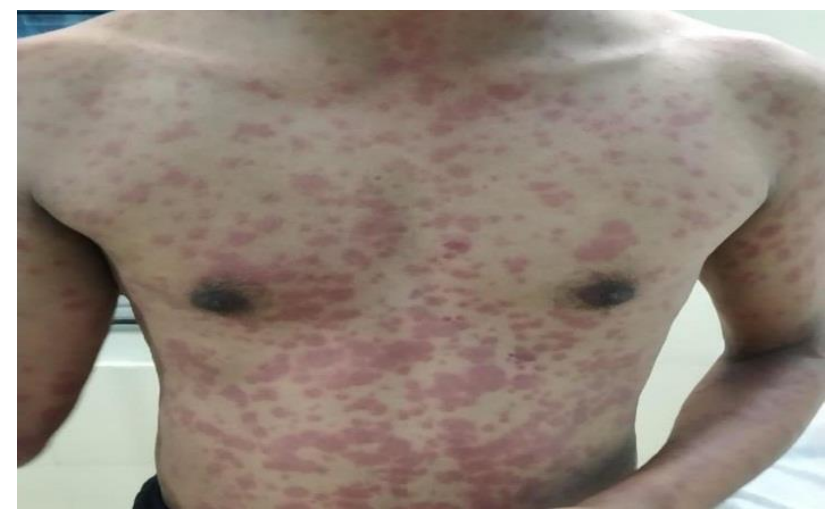

Figure 1: Multiple discrete and confluent erythematous edematous papules and plaques on the trunk and extremities.

Routine investigations were within normal limits. Herpes simplex virus type 1 and type 2 immunoglobulin M (IgM) and immunoglobulin $\mathrm{G}$ (IgG), screening for dengue and leptospirosis, anti-nuclear antibody profile and serology for hepatitis B, C and human immunodeficiency virus were negative. Weil-Felix reaction showed OX-K positivity, but IgM enzyme linked immune-sorbent assay (ELISA) for scrub typhus was negative. Weil-Felix test repeated to check rise in titer was also negative, thus ruling out the possibility of scrub typhus. A final diagnosis of atypical maculopapular rash with urticarial and erythema multiforme-like lesions due to COVID-19 was confirmed and he was treated with oral prednisolone $40 \mathrm{mg}$ daily and hydroxyzine $25 \mathrm{mg}$ twice daily. Skin lesion subsided within three weeks with post inflammatory hyperpigmentation and peeling of the skin of the fingertips. ${ }^{6}$

\section{Case 2}

A 33-year-old female presented with mild fever and itchy multiple erythematous edematous papules and plaques over the body of two days duration. She had history of episodic urticaria sometimes associated with angioedema for last ten years. The patient also had hypothyroidism and was on oral levothyroxine for thirteen years.

On examination the patient was afebrile, vitals were stable. She had multiple wheals over the face, arms and posterior aspect of legs (Figure 2). Rapid antigen test for COVID-
19 was positive. All the known causes of urticaria were ruled out by history, examination and investigations and a final diagnosis of COVID-19 induced urticaria was made. The patient was treated with oral prednisolone $20 \mathrm{mg}$ daily, cetirizine $10 \mathrm{mg}$ at night and ranitidine $150 \mathrm{mg}$ twice daily and wheals subsided within one week.

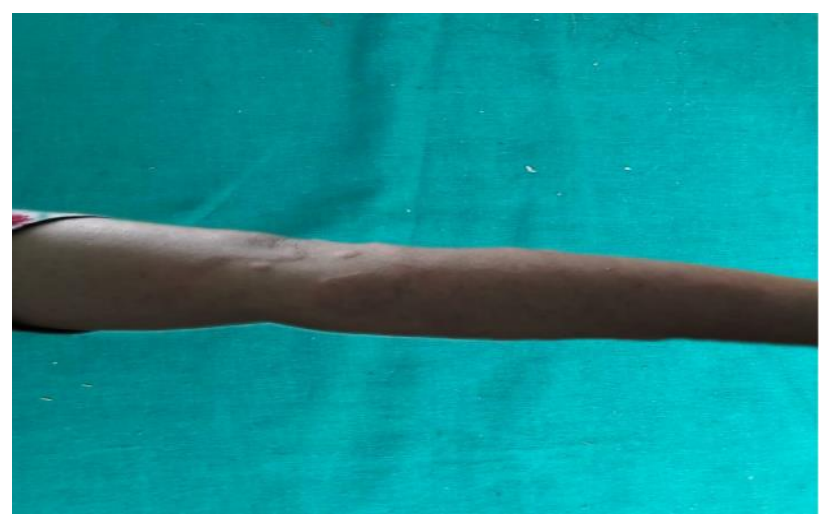

Figure 2: Multiple erythematous edematous papules and plaques on left arm.

\section{Case 3}

A 63-year old male who underwent surgical drainage of liver abscess was diagnosed to have COVID-19 during the second postoperative day. He had no classical symptoms of COVID-19. The patient developed asymptomatic red raised lesions over upper limbs and trunk which appeared first over the shoulder and progressed to involve arms, forearms and chest. Skin lesions developed four days after starting hydroxychloroquine for COVID-19.

On examination the patient was afebrile and vitals were stable. He had multiple discrete erythematous papules over face, upper chest, arms and forearms. Some of the lesions showed a perilesional hypopigmented halo (Figure 3). Routine investigations were within normal limits except for slight elevation of liver enzymes. Diagnosis of eruptive pseudoangiomatosis was made and he was treated with oral cetirizine $10 \mathrm{mg}$ daily and betamethasone cream twice daily. The skin lesions subsided within two weeks.

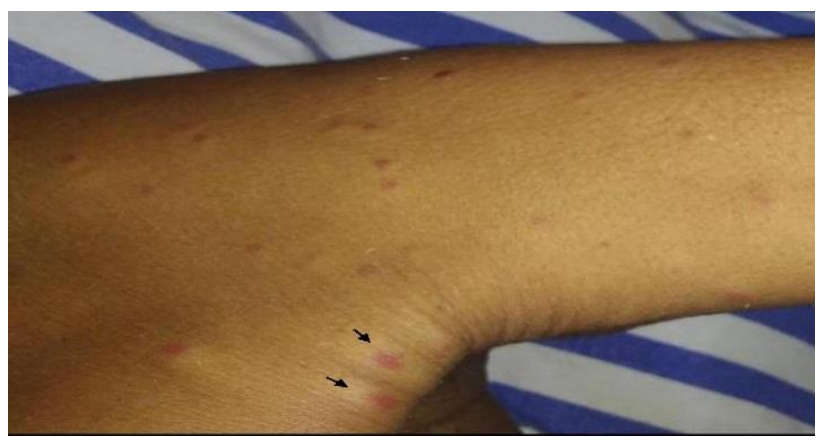

Figure 3: Multiple discrete erythematous papules showing perilesional hypopigmented halo on chest and left arm. 


\section{Case 4}

A 48-year old male returned recently from abroad presented with fever of five days duration and itchy evanescent red raised lesions on trunk of two days duration. He had no other features of COVID-19. He denied history of intake of food items, infections, infestation or inhalation known to cause urticaria prior to the episode. He was treated with hydroxychloroquine, vitamin $\mathrm{C}$, vitamin $\mathrm{D}$ and paracetamol four days ago. $\mathrm{He}$ denied history of similar lesions or other skin lesions in the past.

On examination he had multiple wheals on back of trunk. All routine investigations were normal. Reverse transcriptase polymerase chain reaction (RT PCR) was positive for COVID-19. Diagnosis of acute urticaria due to COVID-19 was suggested and he was treated with cetirizine $10 \mathrm{mg}$ twice daily and wheals subsided within one week. We could not rule out drug induced urticaria in this patient as wheals developed two days after intake of hydroxychloroquine.

\section{Case 5}

A 39-year old male was admitted in the intensive care unit with high grade fever and breathlessness of 20 days duration. He was diagnosed to have right upper lobe pneumonia and was started on empirical antitubercular treatment. He was detected to have hemophagocytic lymphohistiocytosis (HLH) and was treated with systemic corticosteroids. He had type 2 diabetes mellitus and was on insulin for last two years. Rapid antigen test was done as per standard protocol which was positive. He was treated with parenteral ceftazidime, oral trimethoprim with sulfamethoxazole and azithromycin. He presented with multiple itchy red raised lesions over left side of neck of three days duration which gradually progressed to become pustules after two days.

On examination he was febrile and pale. Multiple discrete and confluent pustules were seen on the left side of neck (Figure 4). On investigation hemoglobin was $6.8 \mathrm{~g} / \mathrm{dl}$, total leucocyte count was $6500 / \mathrm{mm}^{3}$, erythrocyte sedimentation rate was $73 \mathrm{~mm}$ per hour and platelet count was 1.1 lakhs $/ \mathrm{mm}^{3}$. Liver and renal function tests were within normal limits. A final diagnosis of acute localized exanthematous pustulosis (ALEP) was made. Antitubercular drugs, systemic antibiotics and systemic steroids were continued and pustules subsided within one week, thus excluding the possibility of drug induced ALEP.

\section{Case 6}

A nine-month old male baby presented with rhinitis and cough of two days duration was diagnosed to have COVID-19. He was treated with salbutamol syrup and saline nasal drops. Next day he developed asymptomatic multiple red raised lesions on extremities. On examination multiple discrete erythematous papules were seen on the arms, legs and thighs. Diagnosis of exaggerated insect bite reaction was made and he was treated with hydroxyzine syrup and hydrocortisone cream and lesions subsided within one week of treatment.

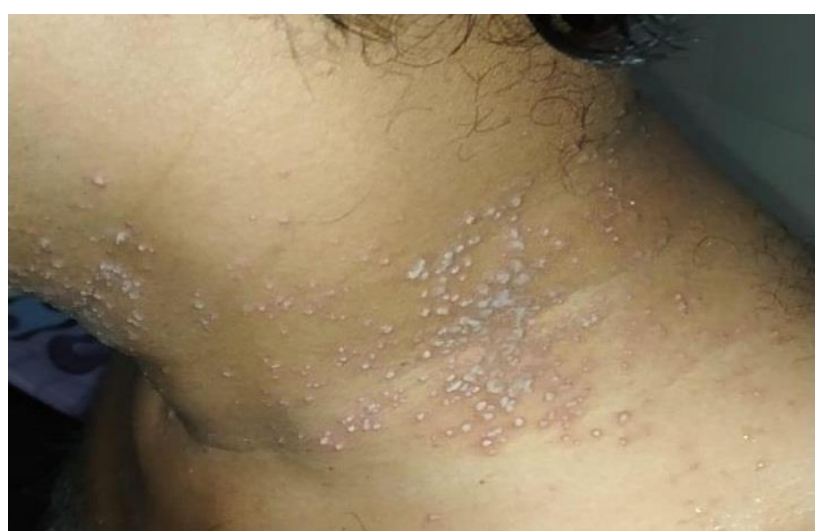

Figure 4: Multiple discrete and confluent pustules on the left side of neck.

\section{DISCUSSION}

A study from Northern Italy showed skin lesions in $20.4 \%$ $(18 / 88)$ patients which included maculopapular rash $(77.8 \%$ or $14 / 18)$, urticaria $(16.7 \%$ or $3 / 18)$ and vesicles $(5.6 \%$ or $1 / 18) .^{2}$ A literature search conducted by Sachdeva et al showed skin lesions as the presenting feature in $12.5 \%(9 / 72)$ patients. They reported maculopapular rash $36.1 \%$ (26/72), papulovesicular lesions $34.7 \%$ (25/72), urticaria 9.7\% (7/72), acral red purple papules $15.3 \%(11 / 72)$, livedo reticularis $2.8 \%$ $(2 / 72)$ and petechiae $1.4 \%(1 / 72){ }^{3}$ A prospective study by Galvan Casas and Catala described five major clinical patterns for rash including maculopapular rash (47\%), urticaria (19\%), pseudo chilblain (19\%), vesicles (9\%) and livedo or necrosis (6\%). Maculopapular rash was reported along with COVID-19 symptoms and was considered as a marker of severe disease. Trunk was the common site of maculopapular rash with sparing of face, palms and soles. Maculopapular rash with many atypical features such as perifollicular distribution, pityriasis rosea-like, erythema elevatum diutinum and erythema multiforme-like lesions were reported. ${ }^{4}$

Cutaneous manifestations were seen in patients of all age groups ranging from nine months to 63 years in this report. Majority of our patients were males with a male to female ratio of 5:1. Most of the patients had mild symptoms of COVID-19 which subsided with symptomatic treatment. All the cutaneous manifestations except maculopapular rash and eruptive pseudoangiomatosis subsided within ten days of treatment. Atypical maculopapular rash noticed in our patient was generalized in distribution with involvement of trunk, limbs, face, palms and soles. The patient also had urticarial and erythema multiforme-like lesions. Maculopapular rash lasted for three weeks and subsided with post inflammatory hyperpigmentation and 
scaling of the skin of the fingertips. Maculopapular rash was the only initial manifestation in this patient and was mistaken for rickettsial infection. ${ }^{6}$

Urticaria was associated with itching in most of the patients and was generalized in distribution. Wheals subsided within one week of treatment. ${ }^{7}$ Our patients also showed similar features. Urticaria was reported in both mild and severe COVID-19.,7 Our patients had mild disease which subsided with symptomatic treatment. Erythema multiforme-like lesions were also reported in COVID-19 patients. Trunk was the initial site and palms and soles were spared. All of them developed rash following treatment of COVID-19 with multiple drugs. ${ }^{8,9}$ Forearm was the initial site in our patient and palms and soles were involved. Erythema multiforme-like lesions were the first sign of COVID-19 and there was no drug intake prior to the skin lesions in our patient. ${ }^{6}$

Erythematous papules with hypopigmented halo were previously described in adrenergic urticaria and eruptive pseudoangiomatosis. ${ }^{10,11}$ Eruptive pseudoangiomatosis induced by viral infection was already described. ${ }^{12}$ Eruptive pseudoangiomatosis was not described in COVID-19 patients so far. Acute generalized exanthematous pustulosis with erythema multiforme-like lesions induced by hydroxychloroquine was described by Robustelli et al. ${ }^{11}$ Acute localized exanthematous pustulosis-like lesion as seen in our patient is not reported so far.

Mechanism of skin lesions in COVID-19 is not fully established. Lymphocytic vasculitis caused by viral particles in blood vessels and immune response to infection leading to Langerhans cell activation are the proposed mechanisms. ${ }^{13}$ Cell mediated immune reaction against viral antigen positive cells could be the possible mechanism of erythema multiforme-like lesions in COVID-19. ${ }^{6}$ High serum concentration of proinflammatory cytokines and markers of coagulation are seen in both urticaria and COVID-19. ${ }^{14-16}$ This could be the reason for increased incidence of urticaria in COVID19 patients.

The major limitation of our report is the inability to perform skin biopsy for histopathological correlation due to fear of spread of infection.

\section{CONCLUSION}

We highlight atypical maculopapular rash with urticarial and erythema multiforme-like lesions, acute localized exanthematous pustulosis-like lesions and eruptive pseudoangiomatosis as new lesions hitherto not reported in COVID-19 patients.

\section{Funding: No funding sources Conflict of interest: None declared Ethical approval: Not required}

\section{REFERENCES}

1. Zhu N, Zhang D, Wang, Li X, Yang B, Song J, et al. A novel corona virus from patients with pneumonia in China2019. N Engl J Med. 2020;382(8):727-33.

2. Recalcati S. Cutaneous manifestations in COVID-19: a first perspective. J Eur Acad. Dermatol Venereol. 2020;34(5):212-3.

3. Sachdeva M, Gianotti R, Shah M, Bradanini L, Tosi $\mathrm{D}$, Veraldi S, et al. Cutaneous manifestations of COVID-19: Report of three cases and review of literature. J Dermatol Sci. 2020;98(2):75-81.

4. Galvan Casas C, Catala A, Hernandez GC, Rodriguez-Jimenez P, Fernandez-Nieto D, Lario RA, et al. Classification of the cutaneous manifestations of COVID-19: a rapid prospective nationwide consensus study in Spain with 375 cases. Br J Dermatol. 2020;183(1):71-7.

5. Wollina U, Karadag AS, Rowland-Payne C, Chiriac A, Lotti T. Cutaneous signs in COVID-19 patients: A review. Dermatol Ther. 2020;33(5).

6. Mariyath OK, Samad KA, Devi K, Surya VS, Effeena MD, Ajina M. Atypical maculopapular rash as the initial sign of COVID-19: A case report from a COVID hospital. J Skin Sex Transm Dis. 2020.

7. Algaadi SA. Urticaria \& COVID-19: A review. Dermatol Ther.2020;14290.

8. Jimenez-Cauhe J, Ortega-Quijano D, CarreteroBarrio I, Suarez-Valle A, Saceda-Corralo D, Moreno-Garcia del Real et al. Erythema multiforme like eruption in patients with COVID-19 infection: clinical and histological findings. Clin Exp Dermatol. 2020;45(7).

9. Robustelli Test E, Vezzoli P, Carugno A, Raponi F, Gianatti A, Rongioletti F, et al. Acute generalized exanthematous pustulosis with erythema multiforme like lesions induced by Hydroxychloroquine in a woman with coronavirus disease 2019 (COVID-19). J Eur Acad Dermatol Venereol. 2020;34(9).

10. Neri I, Patrizi A, Guerrini V, Ricci G, Cevenini R. Eruptive pseudoangiomatosis. $\mathrm{Br} \mathrm{J}$ Dermatol. 2020;143(2):435-8.

11. Kaya G, Lang C. A Case of Adrenergic Urticaria Associated with Vitiligo. Dermatopathology. 2016;3:83-6.

12. Cherry JD, Bobinski JE, Horwath FL, Comerci GD. Acute hemangioma like lesions associated with echoviral infections. Paediatrics.1961;44:498-502.

13. Gianotti R, Zerbi P, Dodiuk-Gad RP. Clinical and histopathological study of skin dermatoses in patients affected by COVID-19 infection in the Northern part of Italy. J Cosmet Dermatol Sci. 2020;98(2):141-3.

14. Wang D, Tang H, Shen Y, Wang F, Lin J, Xu J. Activation of the blood coagulation system in patients with chronic spontaneous urticria. Clin Lab. 2015;61:1283-8.

15. Ucmak D, Akkurt M, Toprak G, Yesilova Y, Turan E, Yildiz I. Determination of dermatology life quality index and serum C-reactive protein and plasma IL-6 
levels in patients with chronic urticaria. Postepy Dermatol Allergol. 2013;30:146-51.

16. Lazzaroni MG, Piantoni S, Masneri S, Garrafa E, Martini G, Tincani A, et al. Coagulation dysfunction in COVID-19: The interplay between inflammation, viral infection and the coagulation system. Blood Rev. 2020;100745.
Cite this article as: Mariyath OKR, Sukumarakurup S, Samad KA, Devi K, Nikhil G, Minu U, et al.

Cutaneous manifestations of COVID-19: experience from a tertiary care center for COVID-19

management in South India. Int J Res Dermatol 2021;7:118-22. 